\title{
A imagem feminina na publicidade de imóvel de luxo: um estudo relacionado ao posicionamento da marca
}

\section{The female image on luxury property advertising: a study related to brand positioning}

\author{
Melina Abu Marrul Mestranda em Administração e Controladoria. Universidade Federal do Ceará (UFC) - Brasil. \\ melina_a@hotmail.com \\ Antonio Rodrigues Albuquerque Mestrando em Administração e Controladoria. Universidade Federal do (eará (UFC) - Brasil. \\ Filho antoniofilhoufc@hotmail.com \\ Maria Maciléya Azevedo Freire Mestranda em Administração e Controladoria. Universidade Federal do Ceará (UFC) - Brasil. \\ macileya@hotmail.com \\ Douglas Heimbecker Mestrando em Administração e Controladoria. Universidade Federal do Ceará (UFC) - Brasil. \\ douglashcastelo@hotmail.com
}

\begin{abstract}
RESUMO
Esta pesquisa tem como objetivo identificar a percepção do prospect quanto à contribuição da utilização da imagem feminina no posicionamento de marca de empreendimento imobiliário de luxo. Para tanto, foi realizada uma pesquisa por meio de entrevista estruturada, qualitativo-descritiva, em Fortaleza - CE, tendo como amostra 12 prospects, selecionados a partir do perfil de consumidor do empreendimento Manhattan Beach Riviera da Construtora Manhattan. Os resultados permitiram perceber que a utilização da imagem feminina em comerciais de empreendimento de luxo é benéfica para a imagem do produto. Outra constatação importante é a necessidade de coerência na comunicação e na transmissão da identidade da empresa com a percepção de imagem da mesma.
\end{abstract}

Palavras-chave: Posicionamento de marca. Imagem feminina. Mercado imobiliário de luxo.

\begin{abstract}
This research aims to identify the perception of prospect clients regarding the contribution of the use of female image in the brand positioning of a luxury real estate enterprise. For that, a research was conducted through a structured, qualitative-descriptive interview in Fortaleza-CE, having as sample 12 prospects, selected from the consumer profile of the Manhattan Beach Riviera project of Construtora Manhattan. The results allowed to realize that the use of the female image in commercials of luxury enterprise is beneficial for the image of the product. Another important observation is the need of coherence in the communication and the transmission of the identity of the company with the perception of the image.
\end{abstract}

Keywords: Brand positioning. Feminine image. Luxury real estate market. 


\section{INTRODUÇÃO}

A marca atua como uma importante ferramenta de uma organização, desta forma, vem sendo utilizada desde a antiguidade como uma maneira de identificar um produto ou serviço de uma empresa (CALDEIRA, 2015), destarte, refletindo demasiadamente na imagem e visão dos diversos clientes e consumidores quanto ao que é apresentado.

Com o passar dos anos, diversas opções de produtos com características e funcionalidades similares surgem no mercado, necessitando criar mais do que uma marca ou símbolo para diferenciá-los (CARMO; MOTTA, 2017), um método de ocupar uma posição na mente e no coração do consumidor. Nesse ínterim, surge a necessidade de criar valor à marca na percepção do cliente (DAVIS, 2000), desta forma, apontando como um importante instrumento de estratégia de marketing utilizado pela organização (CALDEIRA, 2015).

Davis (2000) afirma que a concepção de valor advém de um posicionamento de marca, ou seja, posicioná-la na mente do consumidor criando uma imagem que a diferencia das concorrentes. Este posicionamento parte do pressuposto da visão que se quer representar do negócio no ambiente em que atua e na característica fixada pelos clientes (RANDAZZO, 1997), destarte, exige da empresa uma identidade e definição dos objetivos, assim como a segmentação do mercado-alvo e das oportunidades atrativas (BIEL, 1993). Essa identificação que a empresa incorpora norteia suas ações e deve ser comunicada de forma clara, a fim de que o consumidor tenha uma percepção de imagem coerente com o que fora proposto.

A comunicação do posicionamento de características envolve estratégias e diretrizes a serem adotadas para tomada de decisões assertivas. Diante disso, a comunicação agirá como um instrumento indutor de crenças e posicionamentos, ditando modelos (TYBOUT; STERNTHAL, 2001).

A publicidade é uma das formas que as empresas têm de se comunicar com os clientes, denotando como uma ferramenta na transferência de significados através de uma linguagem que oferta a identidade da organização, mas também cria valor do pressuposto de uma transformação para a vida do consumidor (ROCHA, 2006; RODRIGUES; CARVALHO, 2015), deste modo, girando em torno de uma promessa de felicidade plena, a qual o cliente não possui, mas deseja.

É nesse contexto que a utilização da imagem feminina ganha espaço, um fenômeno social que provocou e segue provocando mudanças sociais e psicológicas (PEREIRA; PRÓCHNO, 2017), que vem influenciando a maneira de ver, vestir, se portar e consumir, compartilhando uma inveja social, oriunda da necessidade de adquirir tal produto (MENESES; MIRANDA, 2015). Aliado a isso, a imagem feminina vem sendo utilizada como marketing de produtos e serviços, como no mercado imobiliário de luxo.

Diante da relevância da temática do posicionamento da marca atrelado à imagem feminina, surgiu o seguinte questionamento do estudo: Qual a percepção do prospect acerca da contribuição da utilização da imagem feminina no posicionamento de marca de um empreendimento imobiliário de luxo? Para responder ao questionamento do estudo, traçou-se como objetivo identificar a percepção do prospect quanto à contribuição da utilização da imagem feminina no posicionamento de marca de um empreendimento imobiliário de luxo.

De acordo com Griffin (1998, p.51-53), "prospect são aqueles que precisam dos produtos ou serviços de uma empresa e estão aptos a comprá-los". Apesar de nunca ter comprado nada, este tipo sabe quem é empresa, onde ela está localizada e o que faz. Os prospects em questão são as pessoas que tem perfil de compra do produto e consequentemente potencial financeiro.

Justifica-se a realização deste estudo pela relevância dos temas posicionamento de marca (CAMPOS; RIBAS, 2014; CALDEIRA, 2015), imagem feminina (MENESES; MIRANDA, 2015; CARMO; MOTTA, 2017) e da carência de estudos que relacionem conjuntamente tais temáticas com o mercado imobiliário (LACERDA, 2018). Ademais, a imagem feminina vem denotando grande representatividade no âmbito empresarial aliado a fatores de publicidade e propaganda (PEREIRA; PRÓCHNO, 2017). Desta feita, o mercado imobiliário de luxo é um segmento que ganha destaque e chama atenção no Brasil. Segundo o banco europeu Halliwell Financial Group, esse segmento aponta-se com relevante potencial para induzir a criação de aproximadamente $R \$ 4,6$ bilhões em negócios até o fim de 2018 (SECOVI-SC, 2013). Nesse ínterim, apresentam representatividade 
considerável, destarte, os resultados encontrados nessa pesquisa poderão fomentar discussões na área acadêmica e contribuir com as informações na área empresarial, auxiliando no processo de tomada de decisão.

\section{REFERENCIAL TEÓRICO}

Neste capítulo serão abordados temas referentes à marca: imagem e posicionamento, assim como da imagem feminina e publicidade.

\subsection{Marca: imagem e posicionamento}

O conceito de marca vem evoluindo ascendentemente ao longo do tempo (DANTAS; MONTE, 2017). Outrora, a marca tinha como finalidade apenas identificar e diferenciar um produto, uma empresa ou um serviço do seu concorrente (PINHO, 1996). Essa finalidade ainda existe, contudo, na atualidade sua definição vai além desse conceito, uma vez que passaram a ser parte significante do patrimônio das organizações sendo fundamentais para o seu crescimento e desenvolvimento, refletindo sobremaneira no seu desempenho e competitividade (MUNIZ; MARCHETTI, 2012).

Nessa perspectiva, as marcas trazem consigo diferenciais competitivos emanados por sua relevância frente aos diversos consumidores sendo considerada um elemento significante na concepção do composto de marketing das organizações e nas experiências que o produto quer oferecer ao consumidor (KAPFERER 2004; DELMONDEZ; DEMO; SCUSSEL, 2017).

Ademais, a marca é um nome, um sinal, um símbolo, um design, ou até mesmo uma combinação desses atributos, com o objetivo de identificar produtos ou serviços de um vendedor ou grupo de vendedores e diferenciá-los de seus concorrentes, sendo a partir disso, reconhecida como uma identidade relacional, pela sua dimensão intersubjetiva oriunda dos processos de troca e negociações, assim como de sua dimensão contratual resultante do reconhecimento de seu valor simbólico e funcional pelos usuários (PEREIRA; VELOSO; MATOS, 2017). Em outros termos, como ponderado por Crescitelli e Figueiredo (2009), as marcas podem agregar valores variados aos diversos usuários, tendo em vista que cada um tem concepções diferentes sobre o significado do valor da marca.

A imagem da marca pode ser definida como a percepção e os atributos que o consumidor reconhece a respeito da marca quando lhe é mencionada ou vista, ou seja, como indicador de procedência e qualidade (MARTINS, 2006; JUNIOR et al., 2015). Essa imagem na percepção do consumidor pode ser construída por diferentes canais, como a experiência de uso do produto, editorias, informações veiculadas pelos meios de comunicação, pontos de venda e publicidade (KELLER, 1993). A comunicação se destaca pelo poder de penetração e de convencimento, já que as mensagens veiculadas são pensadas de acordo com a identidade que a empresa quer transmitir.

Percebe-se que a identidade da marca está relacionada à organização. É como a empresa quer se identificar e posicionar, diferente de imagem da marca que é a percepção que o consumidor faz a respeito da organização e de seus produtos ou serviços. Vásquez (2007) defende que toda imagem é consequência de uma comunicação da marca, se o processo de comunicação coincide com sua identidade, foi realizada uma comunicação ideal, caso contrário, houve uma comunicação distorcida.

De acordo com Silva, Barreto e Facin (2006), outro ponto interessante a ser abordado sobre a imagem da marca é a utilização de celebridades e pessoas em evidência no mundo artístico, esportivo ou cultural, que podem conferir à marca, o prestígio do seu reconhecimento, e ao produto, uma imagem associada, além de reter uma atenção dos consumidores.

A imagem da celebridade influencia e causa uma identificação por parte do público, que busca não apenas o produto, mas o glamour da estrela, porém a escolha dessa celebridade é uma questão peculiar, já que a sua postura na vida privada pode influenciar diretamente na associação com a marca (BYRNE; WHITEHEAD; BREEN, 2003; ESCALAS; BETTMAN, 2005). Para Silvia, Barreto e Facin (2006) o comprador se apropria e integra em sua personalidade parte da alma e do corpo da celebridade, que também influencia em outros aspectos, como comportamento e estilo de cabelo, por exemplo. 
Com uma ampliação do conceito de imagem da marca tem-se o posicionamento da marca, este resulta da comparação e avaliação das marcas concorrentes feitas pelo consumidor (HOOLEY; BRODERICK; MÖLLER, 1998). Em outros termos, a posição na mente é a imagem da marca formada a partir da avaliação do produto em relação a seus concorrentes (DIAS, 2010).

Cabe destacar que o posicionamento da marca, segundo Kotler e Armstrong (2007), pode atuar em três níveis diferentes, sendo estes: atributos do produto, atributo de benefício desejado e, por fim, o atributo de crenças e valores.

Os atributos do produto considerado por Kotler e Armstrong (2007) é o nível baixo de posicionamento, refere-se a um posicionamento da marca baseado nos atributos ligados ao produto, ou seja, suas características de produção. Tendo como exemplo um imóvel de uma construtora, ele pode ser apresentado apenas pelos materiais que foram utilizados para sua construção, ou seja, é um imóvel de alvenaria, com cimento, gesso e esquadrias na varanda e nas janelas dos quartos. Esses atributos representam o nível menos adequado para o posicionamento da marca, devido à matéria-prima estar ao alcance do concorrente e os clientes estarem em busca de benefícios.

O nível de posicionamento por meio dos atributos de benefícios desejados busca ressaltar os desejos do consumidor ao adquirir um determinado produto, ainda como base o mesmo exemplo, o imóvel pode ser apresentado por atributos, tais como: segurança, área de lazer e localização. Essas características de um imóvel são relevantes para o posicionamento e comunicação do produto.

Pode-se também posicionar uma marca, ou produto, por seus atributos de crenças e valores. As marcas bem-sucedidas envolvem o cliente pela emoção. Um imóvel construído por uma pode ser mais que um imóvel. Ele pode transmitir requinte, sofisticação, exclusividade, excelência no acabamento e nos diferenciais, trazendo em si a sofisticação com que a marca pretende posicionar no mercado.

O posicionamento de uma marca de luxo está relacionado à própria marca e a coerência entre sua identidade e imagem. Segundo Vásquez (2007) essa identidade precisa ser bem definida na comunicação e ressaltar os valores intangíveis ligados ela, em vez de abordar associações dos atributos do produto.

Nahás (2009) afirma que o posicionamento deve ser bem definido e transmitido ao público-alvo, ou seja, o consumidor deve compreender claramente o posicionamento da empresa que ele consome. As marcas de luxo buscam constantemente inovação e diferenciais estéticos como forma de se destacar perante os demais produtos.

\subsection{Imagem feminina e publicidade}

O emprego da palavra imagem se remete, na maioria das vezes, à imagem de mídia, mas o seu surgimento vem de longa data, não surgiu apenas a partir da publicidade, sua origem se deu desde o início dos tempos, como artifício para comunicar ideias e sensações. De acordo com Manguel (2006, p. 24), "a imagem dá origem a uma história, que, por sua vez, dá origem a uma imagem".

Para Carvalho (1998, p. 12), "Acima de tudo, publicidade é discurso, linguagem e, portanto, manipula símbolos para fazer a mediação entre objetos e pessoas, utilizando-se mais da linguagem do mercado que a dos objetos". Com uma proposta de suposta transformação na vida do consumidor ao realizar a compra, a publicidade convence que tal objeto tornará o consumidor mais rico mesmo com a controvérsia de estar mais pobre pelo fato de ter gasto o dinheiro. O fato é o produto oferecer uma oportunidade para o consumidor ter uma imagem de si mesmo glamourosa, ou seja, ele tem inveja de si mesmo pelo que poderia ser com o objeto de desejo.

Segundo Berger (1999) a publicidade gira em torno de relações sociais, não em torno de objetos. Sua promessa não é de prazer, mas de felicidade a qual é julgada de fora, por outros. Dessa forma, a publicidade almeja uma insatisfação no atual momento da vida do consumidor, porém nada relacionado a questões sociais, como governo, desemprego, entre outras, e sim oferecer que o consumidor terá uma vida melhor, tornando-se uma versão melhorada.

Klein (2007) corrobora ao afirmar que a publicidade busca imagens que ampliam a percepção do consumidor sobre a realidade, para que este se veja referenciado na peça elucidada. Berger (1999) 
complementa que a linguagem nos anúncios publicitários, transmitem a mensagem, onde, quem não tem condições para consumir torna-se alguém "sem rosto", em contrapartida os que possuem essa condição são "dignos de amor". A publicidade, portanto, tende a relacionar o consumidor ao que consome.

$\mathrm{Na}$ década de 40, as mulheres exibidas nos anúncios traçavam o perfil de uma imagem feminina doméstica, no qual os anúncios abordavam um conceito de estereótipo de "família feliz", o que significava que, se a vida da leitora não fosse similar a supostamente "imposta" na publicidade, a falha, sem dúvidas, seria da sua incapacidade como provedora do lar, em exercer suas funções tanto como esposa como mãe, cabia à mulher, então, a harmonia e o equilíbrio no lar (VESTERGAARD; SCHRODER, 1996).

Segundo Jesus e Almeida (2016), historicamente a imagem da mulher ganha espaço após a Segunda Guerra Mundial, com uma grande mudança no comportamento e no modo de ver a sexualidade. Este foi um período que se deu prioridade às lutas pelo direito ao corpo, ao prazer, e contra o poder dos homens na subordinação das mulheres. A mulher passa a ser vista como cidadã participativa na sociedade e, também, como um membro importante para o desenvolvimento do mercado de consumo.

À medida que a mulher se torna protagonista dessa imagem, acaba sendo vitimizada pela indústria do consumo, tornando-se mulher-imagem-objeto, influenciando a maneira de ver, vestir e se portar. Segundo Berger (1999, p. 94), "a presença social da mulher desenvolveu-se como resultado de sua habilidade em viver sob essa tutela e dentro desse espaço limitado".

Com o passar do tempo, este conceito em anúncios publicitários foi mudando. As mulheres não se limitavam mais apenas às funções de mães e donas de casa, como também trabalhavam fora e pagavam suas contas; o modo antigo de persuasão não surgiu mais efeito na mulher contemporânea.

A partir do ideal de mulher doméstica, percorreu-se o caminho para o ideal de beleza, no qual a publicidade "tira proveito" desse estigma, transformando, segundo Vestergaard e Schroder (1996, p. 83), "na nova camisa-de-força da feminilidade exigindo que a mulheres entrem em competição, mediante a aparência, pela atenção do marido, do namorado, do patrão e de toda espécie masculina".

Em busca dessa beleza, a mulher compartilharia uma relação de inveja de si mesma, imaginando, de acordo com Berger (1999), uma inveja que justifica seu amor próprio, conclui-se que a publicidade rouba o amor que a mulher tem por si própria como ela é, e o oferece de volta pelo preço do produto. $O$ fato das mulheres aceitarem esses preceitos da sociedade do consumo, de acordo com o ponto de vista de Vestergaard e Schroder (1996), levariam essas mulheres a se embelezarem para agradar a elas mesmas, porém a dominação ainda vigente na sociedade e masculina e a libertação que, supostamente, podiam apenas camuflar a realidade, onde os papéis estariam bem-definidos.

Dessa forma, as mulheres vinham se tornando prisioneiras de uma publicidade que ludibriava suas mentes e explorava suas autoestimas, a fim de inseri-las em um contexto social que desejavam. Logo, a publicidade, mais recentemente, tem uma forte influência neste processo, ao difundir estes padrões de beleza idealizados e irreais, ajudando a vender uma beleza que na vida real é inatingível, gerando frustração e infelicidade por parte de algumas mulheres (GOMES et al., 2012).

Em contrapartida, Meneses e Miranda (2015) ressaltam que essa representação da imagem da mulher de beleza padronizada veiculada nas mídias por meio de peças publicitárias de grande alcance com frequência tem sido responsável pela construção de estereótipos que muitas mulheres tentam superar. Por exemplo, a de que a adoção de determinado comportamento e a aquisição de determinados produtos da indústria da beleza aumentariam suas chances de realização pessoal e profissional.

Dessa forma, de acordo com Silva e Costa (2017), levando em conta que a maneira como a mulher é representada na publicidade pode se refletir em nossa sociedade de forma desfavorável, algumas marcas já se adaptam à nova realidade, muito por conta da pressão de consumidores mais críticos em canais como as redes sociais. Gera-se assim a reavaliação e o reposicionamento por parte das marcas em relação à representação da imagem da mulher em sua publicidade.

Em consequência, o público evolui na medida em que a sociedade avança e o discurso usado na publicidade teve que acompanhar as mudanças para o poder dialogar com este público. Logo, a publicidade aos poucos vem constantemente mudando a postura. As antigas abordagens ainda são muito utilizadas, mas enquanto a mulher vem ganhando espaço nos meios sociais, não cabe mais mostrá-la como uma pessoa frágil, 
devota à família, ao lar e à beleza, mas agora como um ser forte, batalhador, independente e empoderado (SILVA; FARIAS, 2017).

\section{METODOLOGIA}

A partir das características da investigação, o estudo pode ser enquadrado como pesquisa descritiva, documental e de abordagem qualitativa. Na medida que, a pesquisa descritiva atua com o objetivo de conhecer e interpretar a realidade sem o uso de manipulação específica das informações (CHURCHILL, 1987). Segundo Helder (2006) o estudo documental encontra-se direcionado a análise de dados que ainda não receberam tratamento. Enquanto a pesquisa qualitativa, de acordo com Flick (2009), trabalha com dados verbais e visuais, de maneira que é direcionada ao estudo de casos concretos utilizando de método temporal e local, analisando elementos nesse contexto.

O empreendimento imobiliário de luxo escolhido para identificar a percepção do prospect foi o Manhattan Beach Riviera, da construtora Manhattan. Esta construtora é considerada um caso de sucesso e uma das melhores construtoras do Nordeste, devido a sua seriedade e alto padrão de qualidade em seus empreendimentos (FRANCO, 2014).

O Manhattan Beach Riviera está localizado no Complexo Aquiraz Riviera na praia de Marambaia em Aquiraz, Estado do Ceará, a 35 minutos do Aeroporto Internacional Pinto Martins, em Fortaleza. Cercado por exuberantes paisagens e belezas naturais, o Complexo Aquiraz Riviera se posiciona como o maior empreendimento turístico de padrão internacional do país (AQUIRAZ RIVIERA, 2014). O empreendimento é voltado para o perfil família e é considerando um imóvel de segunda moradia, sua classificação de perfil de consumidor é classe A, com uma renda mensal mínima de aproximadamente trinta mil reais.

Para a comercialização do empreendimento, a Construtora Manhattan desenvolveu duas campanhas de marketing em momentos e estágios diferentes da obra. A primeira campanha lançada em 2011, período de lançamento do empreendimento, contou com a participação da cantora e compositora Marina Elali, sendo a garota propaganda e atuando em um VT de 30" sobre o empreendimento (identificado na pesquisa como VT1).

No segundo momento, em 2013, fase que antecede em pouco mais de um ano a entrega do empreendimento, foi realizado uma nova campanha de marketing, que foi estrelada pela atriz global Paolla Oliveira, também como peça âncora foi gravado um VT de 30" (identificado na pesquisa como VT2), com imagens dentro do um apartamento decorado bangalô $203 \mathrm{~m}^{2}$ (duplex) que o empreendimento apresenta como showroom.

Para responder à questão de pesquisa deste trabalho, foi realizada uma pesquisa de campo com prospects, utilizando como técnica de coleta de dados a entrevista semiestruturada, por ser a técnica que melhor atende ao objetivo proposto. Para Creswell (2010), esta técnica fundamenta-se em questões não estruturadas, com o intuito de buscar temas e opiniões dos envolvidos. O número de entrevistas não foi préestabelecido. Foram realizadas até o momento em que as pesquisadoras perceberam ter atingindo o ponto de saturação teórica, ou seja, as narrativas não mais contribuem com informações adicionais (CHAMON, 2007). A coleta de dados foi encerrada com um total de 12 entrevistados. Ressalta-se que a amostra foi selecionada de acordo com os critérios econômicos e de classe social, condizentes com perfil de clientes do empreendimento, ou seja, trabalham e pertencem a uma classe social elevada.

Com o auxílio de um tablet, os pesquisadores apresentaram os dois comerciais do Manhattan Beach Riviera (VT1 e VT2) e em seguida a entrevista foi aplicada. Todas foram gravadas, com a permissão dos entrevistados, transcritas na íntegra e tratadas por análise de conteúdo. Iniciou-se com uma identificação dos perfis dos entrevistados através de seis perguntas sociodemográficas: sexo, idade, profissão, estado civil, possui filhos, se sim, quantos. Para a análise deste trabalho, os sujeitos são identificados pelo nome "Entrevistado", se for homem, e "Entrevistada", se for mulher, seguido pela ordem da entrevista e ainda pela sua idade. Exemplo: (Entrevistado 1, 33).

A análise dos dados foi realizada por meio da análise de conteúdo que, segundo Chizzotti (2011), representa uma modalidade de interpretação de texto que visa extrair sentidos e significados através de 
técnicas sistemáticas adequadas. Destaca-se, ainda, que a análise das entrevistas ocorreu com o auxílio do software Atlas.ti 7.0.

\section{APRESENTAÇÃO E ANÁLISE DOS DADOS}

Esta seção contempla a apresentação e análise dos resultados obtidos. Primeiramente, apresentamse os comerciais objeto de estudo da pesquisa. Na sequência, traz as características dos sujeitos participantes. Por último, apresentam-se os resultados obtidos.

\subsection{Apresentação dos comerciais}

Para um melhor entendimento da pesquisa realizada, optou-se em primeiramente descrever os comerciais que foram apresentados aos entrevistados.

O primeiro comercial analisado pelos entrevistados (VT1), faz parte das peças da campanha "Manhattan Beach Riviera: Incomparável", criado pela agência Ponto Inicial, em 2011, e estrelado pela cantora e compositora Marina Elali.

O comercial começa com um plano fechado na mão da cantora acariciando a cortina de um apartamento, em um dia ensolarado, passando a impressão de ser de manhã bem cedo, em seguida a cantora vai andando até uma varanda e a câmera fecha em seu perfil, durante a cena Marina fala, "Viver merece ser incomparável". Marina entra em um salão aberto e, ao fundo, um casal andando, de repente a cena muda para um fim de tarde com um casal de meia idade, tomando vinho em uma mesa ao ar livre, após essa cena.

Marina retorna agora em um carrinho de golfe, dirigido por um professor da modalidade do esporte, e toda vestida para a prática do esporte. A iluminação da cena dá a impressão de ser início de tarde, logo após aparecem duas mulheres jovens com sacolas na mão, olhando uma vitrine e um lettering na tela, village mall. Marina aparece em um restaurante sofisticado, jantando com um casal, depois são apresentadas imagens em perspectivas do empreendimento, tendo cada imagem um lettering com informações a respeito do que é mostrado.

Marina aparece de costas com um chapéu grande na areia olhando para o mar, enquanto as cenas passam Marina continua sua fala, "[...] e por isso MBR traz toda sua sofisticação e elegância para o Aquiraz Riviera, assim a vida ganha um novo tom, sofisticação, Manhattan Beach Riviera, incomparável". Por fim, Marina está na sacada de uma varanda com uma taça de Champagnee assina "Construtora Manhattan mais felicidade por $\mathrm{m}^{2 \prime \prime}$. 
Figura 1 - Marina Elali mostrando a sensação proporcionada pelo empreendimento
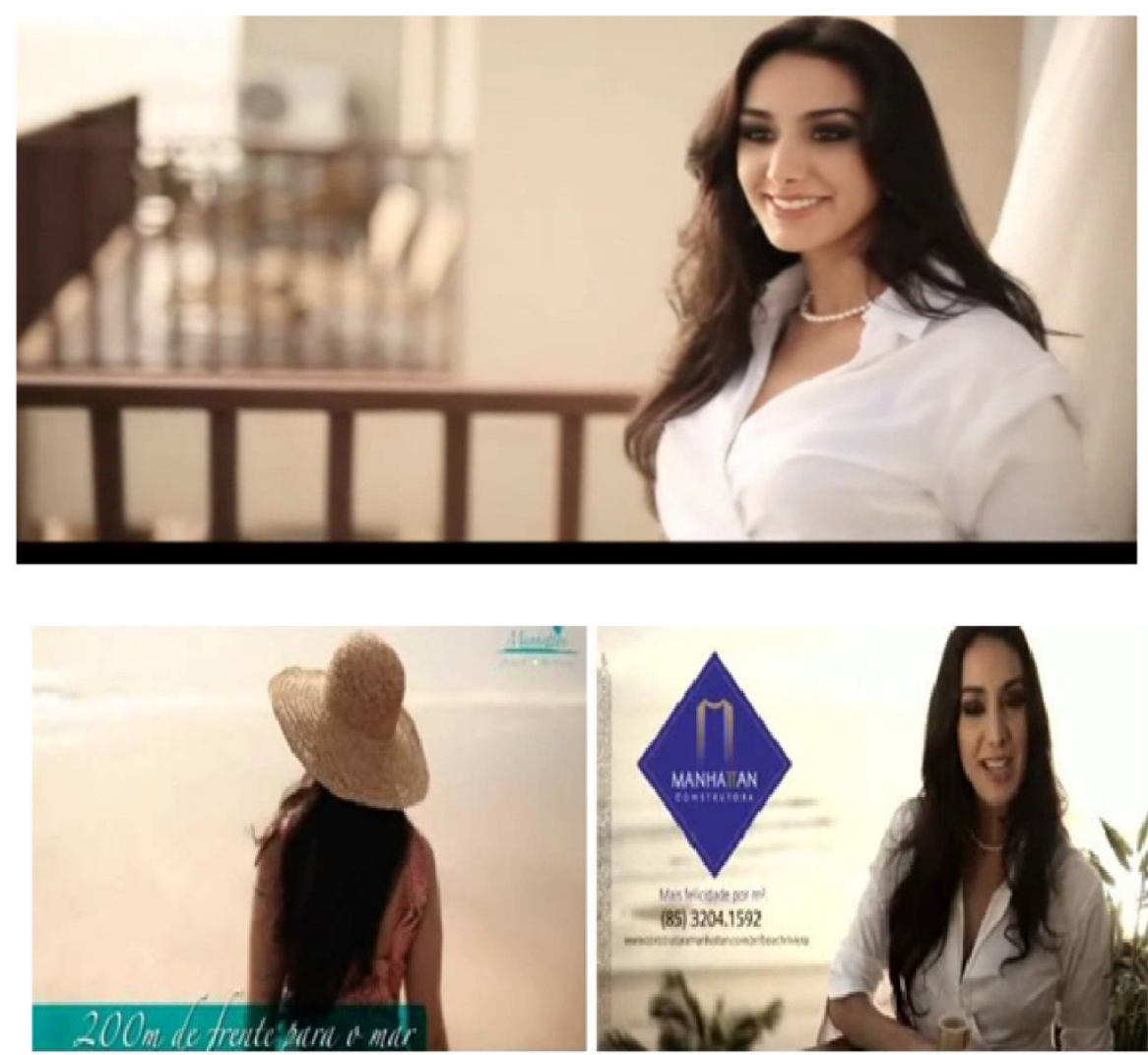

Fonte: Dados da pesquisa (2018).

O segundo comercial (VT2) apresentado para os entrevistados foi o da campanha "Você vai se apaixonar", desenvolvida também pela agência de publicidade e propaganda Ponto Inicial, e veiculada em 2013 e estrelado pela atriz global Paolla Oliveira, com cenas gravadas no próprio complexo onde o empreendimento está inserido e cenas gravadas no apartamento decorado do empreendimento.

O comercial inicia-se com uma cena panorâmica do campo de golfe, vista da janela de um helicóptero, onde o mesmo pousa no heliporto e a atriz Paolla Oliveira desce. A cena seguinte é um plano americano, fechado na atriz com imagens distorcidas ao fundo de jogadores de golfe, no seu discurso a atriz compartilha como gosta de aproveitar o melhor da vida e afirma que no Ceará ela já encontrou o seu lugar, um empreendimento que a fascinou desde o primeiro momento.

As próximas cenas mostram as características do empreendimento, com imagens de crianças pulando na piscina, uma mulher jogando tênis, uma imagem de uma academia e depois um casal jovem tomando um drink na piscina, durante todas essas cenas, Paolla apenas narra e descreve cada item de lazer do Manhattan Beach Riviera.

Após a apresentação das áreas comuns do empreendimento, a próxima cena do comercial é dentro do apartamento decorado, o bangalô duplex de $203 \mathrm{~m}^{2}$, a atriz aparece e fala "você vai se deslumbrar com os apartamentos decorados" na mesma cena tem-se o lettering com as metragens dos apartamentos. Por fim, a atriz Paolla Oliveira assina o comercial andando pela praia em direção à câmera e diz: "Construtora Manhattan, mais felicidade por $\mathrm{m}^{2 \prime \prime}$. 
Figura 2 - Paolla Oliveira apresentando o empreendimento
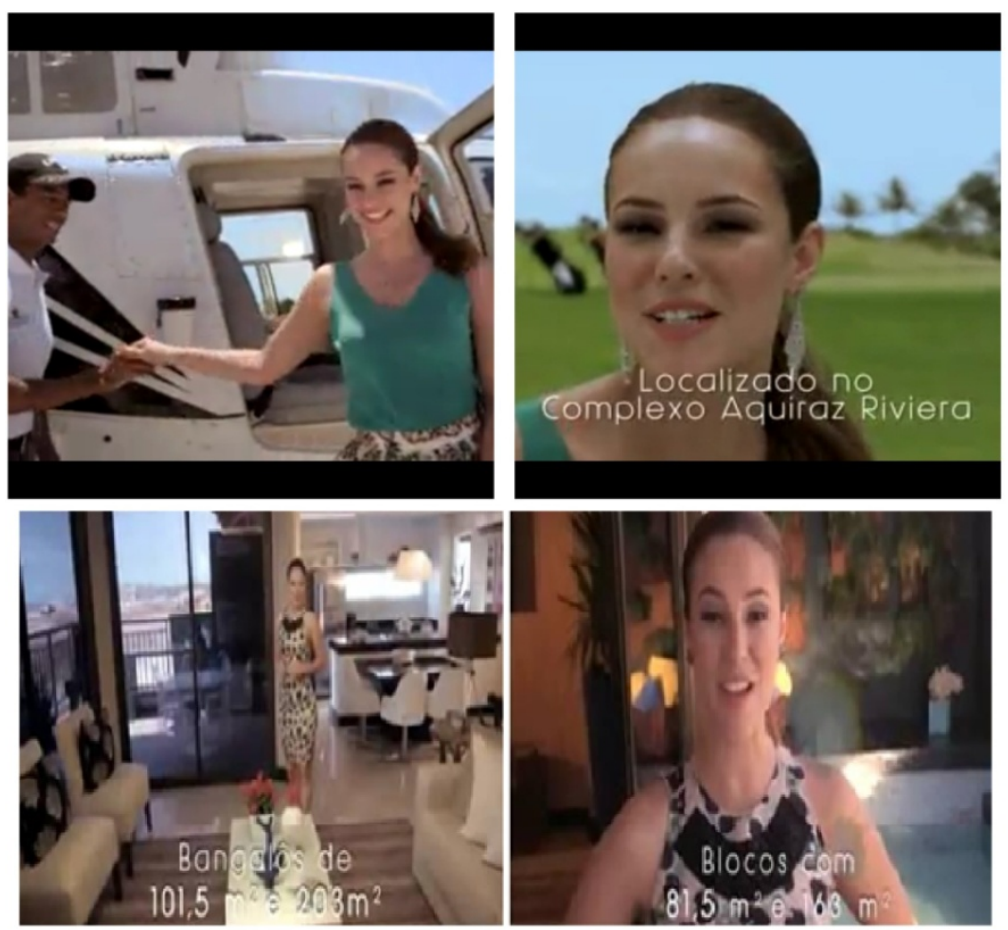

Fonte: Dados da pesquisa (2018).

\subsection{Características dos sujeitos participantes}

Os dados sociodemográficos que caracterizam os prospects que participaram desta pesquisa são apresentados na Tabela 1.

Tabela 1 - Dados Sociodemográficos dos Participantes da Pesquisa

\begin{tabular}{lcllll}
\hline ENTREVISTADOS & IDADE & ESCOLARIDADE & PROFISSÃO & $\begin{array}{c}\text { ESTADO } \\
\text { CIVIL }\end{array}$ & $\begin{array}{c}\text { QUANT. DE } \\
\text { FILHOS }\end{array}$ \\
\hline Entrevistado 1 & 35 & Superior completo & Empresário & Casado & 2 \\
Entrevistada 2 & 59 & Superior incompleto & Servidor publico & Casado & 0 \\
Entrevistado 3 & 64 & Superior completo & Servidor publico & Casado & 3 \\
Entrevistada 4 & 35 & Superior completo & Servidor publico & Casado & 1 \\
Entrevistado 5 & 57 & Superior completo & Empresário & Casado & 3 \\
Entrevistada 6 & 49 & Superior completo & Empresária & Casado & 3 \\
Entrevistada 7 & 37 & Superior completo & Executiva & Casado & 1 \\
Entrevistado 8 & 45 & Superior completo & Servidor publico & Casado & 0 \\
Entrevistada 9 & 39 & Superior completo & Arquiteta & Casado & 0 \\
Entrevistado 10 & 39 & Superior completo & Executivo & Casado & 1 \\
Entrevistada 11 & 34 & Superior completo & Empresária & Casado & 1 \\
Entrevistada 12 & 63 & Superior completo & Empresária & Casado & 4 \\
\hline
\end{tabular}

Fonte: Elaborada pelos autores (2018). 
Os entrevistados que compõem a amostra do presente estudo têm idade entre 34 a 64 anos, sendo 5 homens e 7 mulheres, desses apenas dois homens não têm filhos. Quanto às profissões, foram identificados quatro servidores públicos, cinco empresários, uma arquiteta e dois executivos. Sobre conhecerem a Construtora Manhattan, todos afirmaram conhecê-la.

A segunda pergunta buscou saber se o entrevistado conseguiria identificar se a Construtora Manhattan é direcionada para algum público específico, se sim, qual público seria este, as respostas também foram unânimes, os entrevistados identificam que a construtora é voltada para um público de alto padrão, ou como muitos citaram, públicos A e B. Essas respostas vão de acordo com a conceituação de imagem da marca, que pode ser definida pela percepção e atributos que o consumidor reconhece a respeito da marca quando Ihe é mencionada (PINHO, 1996).

De forma subjetiva, foi perguntado aos entrevistados o que acharam de cada comercial apresentado, 5 entrevistados perceberam que os comerciais se referem ao mesmo empreendimento, e acharam os comerciais bem elaborados, porém 7 entrevistados não identificaram que os comerciais fazem referência ao mesmo produto. Pode-se constatar com as diferentes respostas, a fundamentação que Vásquez (2007) defende, que a imagem é consequência de uma comunicação da marca, se o processo de comunicação coincide com a identidade da marca, ou seja, com o a empresa quer transmitir, foi realizada uma comunicação ideal, caso contrário, houve uma comunicação distorcida. Neste caso, percebe-se uma distorção entre os comerciais apresentados, por se tratar de um mesmo empreendimento (produto) e 4 dos entrevistados, não terem percebido isso.

A quarta pergunta, questionou se o entrevistado saberia dizer quem é a apresentadora de cada comercial. Com relação ao VT1 apenas um entrevistado identificou o nome da apresentadora e dois dos entrevistados disserem saber quem é, mas não recordavam o nome. Já o VT2 nove dos dez entrevistados afirmaram saber quem é a apresentadora. Silva, Barreto e Facin (2006) defendem que a utilização de celebridades ou pessoas em evidência no mundo artístico podem conferir para uma marca ou produto o prestígio do seu reconhecimento e uma imagem associada, com a personalidade, além de reter uma atenção dos consumidores e podendo influenciar o público que busca não apenas o produto, mas o glamour que a celebridade confere a ele. Nesta pesquisa, percebe-se que apenas a utilização da imagem da Paolla Oliveira conferiu ao comercial retenção da atenção por parte dos entrevistados.

A quinta pergunta era referente à identificação e à descrição do estilo de vestir, postura e imagem das apresentadoras de cada comercial. Os respondentes foram categóricos ao afirmar que a atriz Paolla Oliveira estava adequada ao ambiente, mas que a cantora Marina Elli não apresentou uma produção adequada, com maquiagem forte e roupa inadequada.

\begin{abstract}
A Paolla é de uma beleza simples e natural, vestida com uma saia solta, blusa sem manga, muito sofisticada combinando com o clima de praia sofisticada que ela estava. Eu vejo o comercial da Marina Elali, ela com muita maquiagem não condizendo com a praia, muito produzida, de uma beleza não natural, mas simpática (Entrevistada 9, 39).
\end{abstract}

\begin{abstract}
A Paolla está mais adequada para propaganda que é numa praia, roupa sem manga, eu acho que ela passa algo mais solto, descontraído, o modo de falar, simpática. A outra eu achei muito fashion, muito maquiada para uma praia, muito arrumada e a Paolla é loira combina mais com a praia (Entrevistada 6, 49).
\end{abstract}

Nesse contexto, cabe ressaltar que à medida que a mulher se torna protagonista dessa imagem, acaba sendo vitimizada pela indústria do consumo, tornando-se mulher-imagem-objeto, influenciando a maneira de ver, vestir e se portar. Segundo Berger (1999, p. 94), "a presença social da mulher desenvolveu-se como resultado de sua habilidade em viver sob essa tutela e dentro desse espaço limitado". A resposta da entrevistada 6 confirma o pensamento de Berger (1999), o qual afirma que a publicidade apresenta um ideal 
de beleza quase que intangível, que não valoriza a beleza natural e usa de artifícios como maquiagem para transmitir o ideal de beleza.

Percebeu-se com as respostas, uma contradição ao pensamento de Vestergaard e Schroder (1996), sobre os anúncios direcionados ao público masculino de modo geral, utilizarem a imagem feminina e sua beleza a um sinal de inferioridade ou dependência, o que não foi percebido nos comerciais.

Perguntou-se na percepção do entrevistado, a imagem de cada apresentadora condiz com a imagem do empreendimento, para alguns entrevistados essa pergunta teve resposta na pergunta anterior. Conforme algumas respostas transcritas a seguir:

\begin{abstract}
A Paolla condiz, porque o empreendimento é classe A e ela combina com esse perfil de empreendimento, a outra apresentadora condiz em parte, por ela ser bonita e apresentar bem, mas ela não combinou com o fato do empreendimento ser na praia, estava muito sofisticada (Entrevistada 6, 49)
\end{abstract}

Eu achei que a imagem da Paolla condiz com o empreendimento, porque eu achei ele mais descontraído, praiano ideal para passar as férias, já apresentadora 1 condiz com o primeiro empreendimento, eu não o conheço mas parece bem sofisticado como ela, com um restaurante chique, ela toda elegante jantando (Entrevistada 7, 37).

As percepções dos entrevistados concordam com Lima e Carvalho (2010), que defendem o posicionamento como algo que a empresa ou marca faz dentro da mente do consumidor em perspectiva, em outras palavras, como a marca posiciona o produto na mente do consumidor em todo o seu potencial.

A sétima pergunta foi acerca dos comerciais, sendo realizada para uma resposta objetiva, porém alguns entrevistados dissertaram sobre ela. Buscou-se entender se os comerciais transmitiram os atributos do produto, os benefícios desejados pelos clientes e as crenças e valores da Construtora Manhattan, todos os entrevistados afirmaram terem percebido os três níveis de atributos nos dois comerciais, porém o VT2 transmitiu de forma mais clara e direta, conforme observado nas respostas a seguir:

\footnotetext{
O comercial 2 parece ter mais tempo e transmitiu bem mais que o 1 os atributos do produto, quanto aos benefícios desejados, o comercial 2 falou muito mais das características do empreendimento, como metragens e áreas comuns, já o comercial 1 ressaltou um pouco melhor o fato do empreendimento estar situado no Aquiraz Riviera, quanto as crenças e valores os dois transmitiram a sofisticação, mas o 2 de uma forma mais clara e acessível (Entrevistado 10, 39).
}

Achei que o comercial 2 passa mais os atributos dos produtos e os benefícios desejados, o comercial 1 eu achei muito fechado, as cenas mais marcantes para mim são no apartamento. Quanto as crenças os dois transmitem a sofisticação, os dois mostram um helicóptero (Entrevistada 6, 49).

Os níveis de classificação do posicionamento de uma marca ou produto, segundo Kotler e Armstrong (2007), é definido como estratégia da empresa é como ela quer ser percebida no mercado uma posicionamento baseado nos atributos ligados ao produto, ou seja, nas suas características de produção, não dão segurança a uma marca ou produto, pois os commoditiesutilizados na produção podem ser de fácil acesso aos concorrentes. O nível de posicionamento por meio dos atributos de benefícios desejados busca ressaltar os desejos do consumidor ao adquirir um determinado produto, ou seja, diferencia que aquele produto tem os atributos de crenças e valores, utiliza a emoção, felicidade, sofisticação, exclusividade para envolver os clientes.

Com o intuito de responder o objetivo geral deste estudo a oitava pergunta busca saber se o fato do empreendimento nos comerciais 1 e 2 serem apresentados por mulheres é benéfico ou não para a imagem do 
empreendimento, e o porquê. Foi criada uma unidade de registro, que pode ser vista por meio da Figura 3 que ilustra a percepção dos entrevistados via análise de conteúdo de suas respostas sobre a utilização da imagem feminina.

Figura 3 - Utilização da imagem feminina

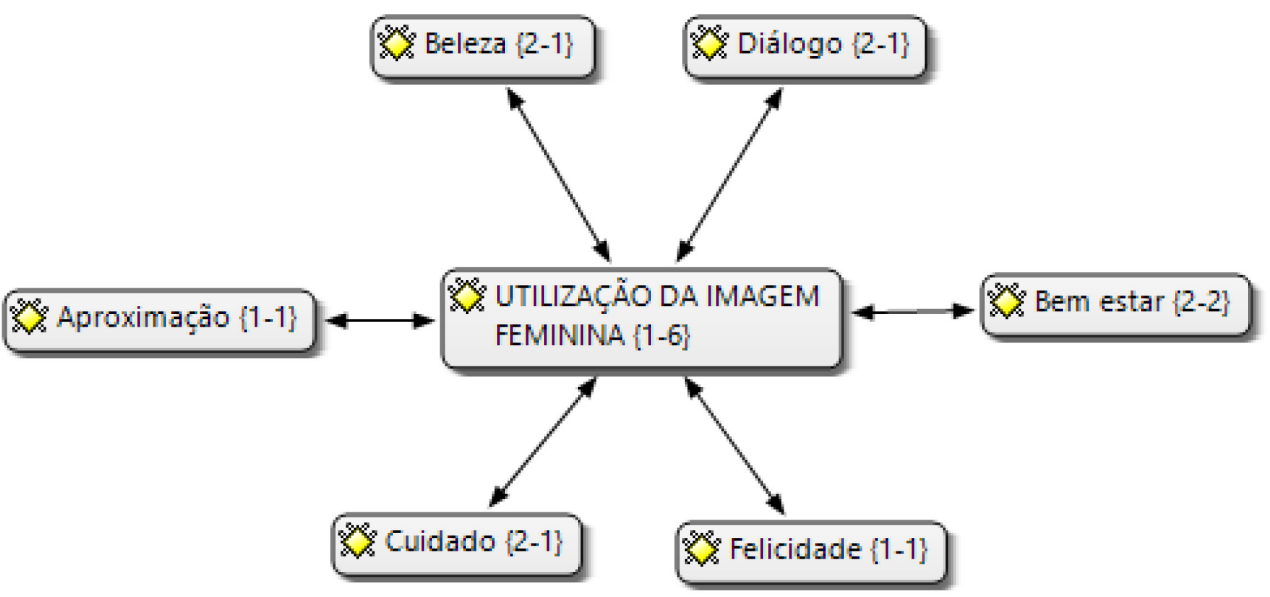

Fonte: Elaborada pelos autores (2018).

Por meio da Figura 3 infere-se que, para os entrevistados, a utilização da imagem feminina nos comerciais representa um cuidado por parte do empreendimento, sendo destacado duas vezes, assim como a beleza da mulher e sua capacidade de diálogo considerados fatores-chave para o sucesso da imagem do empreendimento. Assim, surgiu nos discursos dos entrevistados, o reconhecimento dos benefícios da utilização dessas características, sendo que tais fatores (cuidado, beleza e diálogo) podem proporcionar uma comunicação tanto com o público masculino quanto com o público feminino.

Ademais, ressalta-se que o bem-estar transmitido pela imagem feminina, agrega positivamente no posicionamento do negócio, sendo destacado por dois dos entrevistados. Portanto, é relevante destacar que dez dos entrevistados entenderam como algo benéfico a utilização da imagem feminina na apresentação de comerciais, enquanto apenas dois destacaram não influenciar. Algumas dessas constatações podem ser visualizadas conforme as respostas a seguir:

Sim, porque a mulher é mais detalhista, cuidadosa com os filhos o marido, tem um papel de cuidado e preocupação com o melhor para família. (Entrevistada 9, 39).

Demais, a mulher olha para outra, porque quando vejo uma mulher falando acho que tem alguma coisa interessante para mim, a gente gosta de saber as dicas de outras mulheres (Entrevistada 7, 37)

Segundo Vestergaard e Schroder (1996) e atualmente ponderado por Silva e Farias (2017) a propaganda traz uma imagem da mulher considerada moderna, que trabalha fora, toma suas próprias decisões e ainda cuida das atividades domésticas em vez de dar ênfase à imagem da mulher apenas doméstica. Mas as mulheres parecem ter se tornado prisioneiras de uma publicidade que ludibria suas mentes, explora a autoestima e utiliza de artifícios que envolvem uma suposta conquista da felicidade baseada em um padrão de beleza inatingível, e quem sabe assim estarão inseridas em um contexto social que desejam.

Por fim, a última pergunta realizada aos entrevistados foi se os comerciais despertavam interesse em conhecer o empreendimento. Todos os entrevistados afirmaram que ambos os comerciais despertam. 
Percebe-se que os anúncios de publicidade relacionam a imagem da mulher bela e seus traços de feminilidade com o intuito de atrair e reter a atenção dos consumidores. Berger (1999) afirma que a publicidade se utiliza da sexualidade para vender um produto, e uma suposta felicidade que permite ser comprada, onde ter o poder de comprar é o mesmo que ser desejado, na forma sexual do desejo.

\section{CONSIDERAÇÕES FINAIS}

A utilização da imagem feminina na publicidade é algo recente, advindo das conquistas vividas pelas mulheres do século passado, momentos históricos e de luta, por liberdade sexual, por participação nas políticas públicas e pelo direito de voz e voto, que influenciaram a publicidade e o modo de ver e configurar a imagem feminina.

Neste contexto, esta pesquisa pôde identificar a percepção do prospect quanto à contribuição da utilização da imagem feminina no posicionamento de marca de um empreendimento imobiliário de luxo. Percebeu-se que as imagens femininas, explanadas nos comerciais do empreendimento, exerceram um papel benéfico na comunicação do produto. Analisou-se também que a figura feminina em propagandas passa para o mercado em questão um diálogo mais próximo, com uma linguagem mais receptiva, visto que tanto o homem quanto a mulher se identificam com a figura feminina próspera, moderna, que trabalha fora, toma suas próprias decisões com cuidado e atenção e que irradia vida e alegria.

Os conceitos de imagem da marca também estiveram presentes na análise, sendo constatado que a Construtora Manhattan transmite, em seus comerciais, um posicionamento coerente com relação a sua identidade e à imagem de marca percebida pelo prospect. Ressalta-se ainda, que as associações intangíveis da empresa foram percebidas de forma clara pelos prospects entrevistados, sendo tais associações como sofisticação, beleza, felicidade, bem-estar, características emocionais, fatores positivos, que causam impacto no comportamento do consumidor.

Acredita-se que este trabalho possa ser instrumento de consulta para outros trabalhos acadêmicos e possa contribuir como ferramenta para diretrizes na área empresarial, como base de pesquisa e aprofundamento sobre posicionamento de marca e a imagem e o papel do gênero feminino na sociedade e suas repercussões junto à publicidade.

Como limitação deste estudo destaca-se a amostra e como sugestão a pesquisas posteriores a este trabalho, entende-se como importante analisar a contribuição da utilização da imagem feminina em empreendimento imobiliários voltados para classe $C$ e D, podendo assim ser feito um comparativo a partir da percepção por diferentes classes sociais. Outra sugestão para uma nova pesquisa baseia-se na imagem do transmitida do empreendimento nas peças publicitárias e sua influência e conversão para a decisão de compra do produto.

\section{REFERÊNCIAS}

AQUIRAZ RIVIERA. Institucional. Disponível em: http://www.aquiraz-riviera.com/pt/aquirazriviera/institucional. Acesso em: 20 abr. 2014.

BERGER, J. Modos de ver. Rio de Janeiro: Rocco, 1999.

BIEL, A. L. Converting image into equity. Brand equity and advertising: Advertising's role in building strong brands, v. 26, n. 10, p. 67-81, 1993.

BYRNE, A.; WHITEHEAD, M.; BREEN, S. The naked truth of celebrity endorsement. British Food Journal, v. 105, n. 4/5, p. 288-296, 2003.

CALDEIRA, L. G. Posicionamento e imagem de marca no mercado de café verde. 2015. Tese (Doutorado) Universidade Federal de Lavras, Lavras, 2015. 
CAMPOS, A. Q. C. Q.; RIBAS, L. S. R. G. S. Tendências de moda e posicionamento de marca. ModaPalavra eperiódico, v. 7, n. 13, p. 187-209, 2014.

CARMO, L. G.; MOTTA, R. C. "Mulheres reais" nas campanhas publicitárias da marca Dove: o padrão de beleza feminino em xeque. Revista Formadores - Vivências e Estudos: Caderno de Iniciação Científica, Cachoeira, Bahia, v. 10, n. 1, p. 87 - 101, mar. 2017.

CARVALHO, N. Publicidade a linguagem da sedução. São Paulo: Ática, 1998.

CHAMON, E. M. Q. O. Representação social da pesquisa e da atividade científica: um estudo com doutorandos. Estudos de Psicologia, v. 12, n. 1, p. 37-46, 2007.

CHIZZOTTI, A. Pesquisa qualitativa em ciências sociais humanas e sociais. 4. ed. Petrópolis: Vozes, 2011.

CHURCHILL JR., G.A. Marketing research: methodological foundations. Chicago: The Dryden Press, 1987.

CONSTRUTORA MANHATTAN. Manhattan Beach Riviera. 11 nov. 2013. Disponível em: https://www.youtube.com/watch?v=f4evGBP2p6I. Acesso em: 20 abr. 2014.

CRESCITELLI, E.; FIGUEIREDO, J.B. Brand equity evolution: a system dynamics model. BAR-Brazilian Administration Review, v. 6, n. 2, p. 101-117, 2009.

CRESWELL, J. W. Projeto de pesquisa: métodos qualitativo, quantitativo e misto. 3. ed. Porto Alegre: Artmed, 2010.

DANTAS, A. P.; MONTE, W. S. Empoderamento e posicionamento de marca: uma análise da marca Lola Cosmetics. REUNIR: Revista de Administração, Contabilidade e Sustentabilidade, v. 7, n. 3, 2017.

DAVIS, S. M. Brand asset management: Driving profitable growth through your brands. San Francisco: Jossey-Bass, 2000.

DELMONDEZ, F.; DEMO, G.; SCUSSEL, F. B. C. Você é o que Você Vende: A Influência da Personalidade de Marca no Relacionamento com Clientes de Empresas de Fast-Food. Revista Brasileira de Marketing, v. 16, $\mathrm{n}$. 4, p. 563-578, 2017.

DIAS, S. R. (coord.). Gestão de marketing. 2. ed. São Paulo: Saraiva, 2010.

ESCALAS, J. E.; BETTMAN, J. R. Self-construal, reference groups, and brand meaning. Journal of consumer research, v. 32, n. 3, p. 378-389, 2005.

FLICK, U. Uma introdução à pesquisa qualitativa. 3. ed. Porto Alegre: Bookman, 2009.

FRANCO, L. Mercado imobiliário: o shopping de imóveis do Ceará. Jornal O Povo, 26 abr. 2014.

GOMES, K. R.; BONETTI, T. C.; OLIARI, D. E.; ANNUSECK, M. R. Ofertas de Felicidade e Modelos de Beleza na Propaganda Feminina. In: INTERCOM - CONGRESSO BRASILEIRO DE CIÊNCIAS DA COMUNICAÇÃO, 35., 2012, Fortaleza. Anais [....]. Fortaleza, 2012.

GRIFFIN, Jill. Como conquistar e manter o cliente fiel - Transforme seus clientes em verdadeiros parceiros. São Paulo: Futura, 1998.

HELDER, R. R. Como fazer análise documental. Porto: Universidade de Algarve, 2006.

HOOLEY, G.; BRODERICK, A.; MÖLLER, K. Competitive positioning and the resource-based view of the firm. Journal of strategic marketing, v. 6, n. 2, p. 97-116, 1998. 
JESUS, C. C.; ALMEIDA, I. F. O Movimento Feminista e as redefinições da mulher na sociedade após a Segunda Guerra Mundial. Boletim Historiar, n. 14, p. 9-26, 2016.

JÚNIOR, C. B. E.; FEDER, L.; OLIVEIRA, E. T.; FRANÇA, G. M. Marca, o elemento de familiarização entre cliente e empresa. In: CONGRESSO BRASILEIRO DE CIÊNCIAS DA COMUNICAÇÃO, 38., 2015. Aprapicon,1-15, Fortaleza. Anais [....]. Fortaleza, 2015.

KAPFERER, J. The new strategic brand management. Creating and sustaining brand equity long term. London, UK: Kogan Page, 2004. v. 3.

KELLER, K. L. Conceptualizing, measuring, and managing customer-based brand equity. Journal of marketing, v. 57, n. 1, p. 1-22, 1993.

KLEIN, A. Cultura da visibilidade entre a profundidade das imagens e a superfície dos corpos. In: MÈDOLA Ana Sílvia Lopes; ARAÚJO, Denize Correa; BRUNO, Fernanda (org.). Imagem, visibilidade e cultura midiática. Livro da XV Compôs. Porto Alegre: Sulina, 2007. p. 81-92.

KOTLER, P.; ARMSTRONG, G. Princípios de marketing. Trad. Cristina Yamagami. 12. ed. São Paulo: Pearson Prentice Hall, 2007.

LACERDA, N. Mercado imobiliário de bens patrimoniais: um modelo interpretativo a partir do centro histórico do Recife (Brasil). EURE (Santiago), v. 44, n. 132, p. 89-108, 2018.

LIMA, G. B.; CARVALHO, D. T. Estratégias de marketing e posicionamento de marca no setor hoteleiro: um estudo exploratório. REMark - Revista Brasileira de Marketing, São Paulo, v. 9, n. 3, p 98-126, set./dez. 2010.

MANGUEL, A. Lendo imagens. São Paulo: Companhia das Letras, 2006.

MARTINS, J. R. Branding: um manual para você criar, gerenciar e avaliar marcas. São Paulo: Global Brands, 2006.

MENESES, V. D.; MIRANDA, C. M. Reflexões sobre a cultura da imagem e o imaginário feminino na publicidade. Revista Observatório, v. 1, n. 1, p. 171-193, 2015.

MUNIZ, K. M.; MARCHETTI, R. Z. Brand personality dimensions in the Brazilian context. BAR-Brazilian Administration Review, v. 9, n. 2, p. 168-188, 2012.

NAHÁS, É. K. B. Estratégias de marketing no mercado de luxo: um estudo exploratório com consultores do setor. 2009. 129 f. Dissertação (Mestrado em Administração) - Universidade Metodista de Piracicaba. Piracicaba, 2009.

PEREIRA, A. A. S.; PRÓCHNO, C. C. S. C. Sentidos Produzidos a partir do Discurso sobre o Corpo Feminino na Publicidade. Revista Subjetividades, v. 17, n. 2, p. 76-86, 2017.

PEREIRA, J. R., VELOSO, C., MATOS, E. B. A. Percepção de Marcas de Luxo em uma Era de "Populismo" de Réplicas: um Estudo a Partir da Ancoragem de Preços. Revista Organizações em Contexto, v. 13, n. 26, p. 259-290, 2017.

PINHO, J. B. O poder das marcas. São Paulo: Summus, 1996. v. 53.

RANDAZZO, S. A criação de mitos na publicidade. Rio de Janeiro: Rocco, p. 91-137, 1997.

ROCHA, E. P. Guimarães. Representações do consumo: estudos sobre a narrativa publicitária. Mauad Editora Ltda, Rio de Janeiro, 2006. 
RODRIGUES, A. I.; CARVALHO, A. Desde a década de setenta, em setenta comerciais: as representações LGBT na publicidade e propaganda veiculadas na televisão brasileira. In: ENCONTRO NACIONAL DE HISTÓRIA DA MÍDIA, Porto Alegre. Anais [...]. Porto Alegre, RS: Alcar, 2015.

SCOTT, J. W. Gênero: uma categoria útil de análise histórica. Educação e Realidade, Porto Alegre, n. 20, v. 2, p. 71-99, jul./dez. 1995.

SILVA, M. A. R.; COSTA, L. R.C. Publicidade, empoderamento feminino e o reposicionamento da cerveja Itaipava. Paraíba: Temática, 2017.

SILVA, D. R.; BARRETO, M. J.; FACIN, T. C. A fada madrinha da realidade. In: SIMPÓSIO DE CIÊNCIAS DA COMUNICAÇÃO NA REGIÃO SUDESTE, 11., 2006, Ribeirão Preto. Anais [...]. Ribeirão Preto: Sociedade Brasileira de Estudos Interdisciplinares da Comunicação, 2006.

SILVA, M. A. R.; FARIAS, W. C. B. A concepção do feminino na publicidade contemporânea: estudo de caso da campanha \#LikeAGirl da Always. Paraíba: Temática, 2017.

SINDICATO DAS EMPRESAS DE COMPRA, VENDA, LOCAÇÃO E ADMINISTRAÇÃO DE IMÓVEIS E DOS CONDOMÍNIOS RESIDENCIAIS E COMERCIAIS DE SANTA CATARINA (SECOVI-SC). Mercado imobiliário de luxo cresce no Brasil. 06 fev. 2013. Disponível em: http://www.secovi-sc.com.br/noticias.php?id_noticia=37.

Acesso em: 20 abr. 2014.

TYBOUT; A.; STERNTHAL, B. Brand Positioning. In: IACOBUCCI, D. (org.). Kellog on marketing. New York: John Wiley, p. 260-295. 2001.

VÁSQUEZ, R.P. Identidade de marca, gestão e comunicação. Organicom, ano 4, n. 7, p. 199-211, jul./dez. 2007.

VESTERGAARD, T.; SCHRODER, K. A linguagem da propaganda. São Paulo: Martins Fontes, 1996. 